\title{
Burden of cumulative risk factors associated with non-communicable diseases among adults in Uganda: evidence from a national baseline survey
}

Ronald Wesonga ${ }^{1,7^{*}}$, David Guwatudde ${ }^{2}$, Silver K. Bahendeka ${ }^{3}$, Gerald Mutungi ${ }^{4}$, Fabian Nabugoomu ${ }^{5,7}$ and James Muwonge ${ }^{6}$

\begin{abstract}
Background: Modification of known risk factors has been the most tested strategy for dealing with noncommunicable diseases (NCDs). The cumulative number of NCD risk factors exhibited by an individual depicts a disease burden. However, understanding the risk factors associated with increased NCD burden has been constrained by scarcity of nationally representative data, especially in the developing countries and not well explored in the developed countries as well.

Methods: Assessment of key risk factors for NCDs using population data drawn from 3987 participants in a nationally representative baseline survey in Uganda was made. Five key risk factors considered for the indicator variable included: high frequency of tobacco smoking, less than five servings of fruit and vegetables per day, low physical activity levels, high body mass index and raised blood pressure. We developed a composite indicator dependent variable with counts of number of risk factors associated with NCDs per participant. A statistical modeling framework was developed and a multinomial logistic regression model was fitted. The endogenous and exogenous predictors of NCD cumulative risk factors were assessed.

Results: A novel model framework for cumulative number of NCD risk factors was developed. Most respondents, $38.6 \%$ exhibited one or two NCD risk factors each. Of the total sample, $56 \cdot 4 \%$ had at least two risk factors whereas only $5.3 \%$ showed no risk factor at all. Body mass index, systolic blood pressure, diastolic blood pressure, consumption of fruit and vegetables, age, region, residence, type of residence and land tenure system were statistically significant predictors of number of NCD risk factors $(p<0 \cdot 05)$. With exception to diastolic blood pressure, increase in age, body mass index, systolic blood pressure and reduction in daily fruit and vegetable servings were found to significantly increase the relative risks of exhibiting cumulative NCD risk factors. Compared to the urban residence status, the relative risk of living in a rural area significantly increased the risk of having 1 or 2 risk factors by a multiple of 1.55 .

(Continued on next page)
\end{abstract}

\footnotetext{
* Correspondence: wesonga@wesonga.com

${ }^{1}$ School of Statistics and Planning, Makerere University, Kampala, Uganda

${ }^{7}$ East African Statistics Institute, Kampala, East Africa, Uganda

Full list of author information is available at the end of the article
} 
(Continued from previous page)

Conclusions: The non-communicable disease burden is on the increase, with more participants reporting to have at least two risk factors. Our findings imply that, besides endogenous factors, exogenous factors such as region, residence status, land tenure system and behavioral characteristics have significant causal effects on the cumulative NCD risk factors. Subsequently, while developing interventions to combat cumulative risk factors of NCDs, the Ministry of Health needs to employ a more holistic approach to facilitate equitable health and sensitization across age, residence and regional divide.

Keywords: Non-communicable diseases, Cumulative risk factors, Disease burden, Prevalence, Uganda

\section{Background}

World Health Organization (WHO), has recognized that it's a right of every human being to live a healthy life [1]. However, based on the research evidence, a number of risk factors associated with non-communicable diseases (NCDs) jeopardize lives of millions of people world-wide $[2,3]$. There are differences in risk factors exhibited per person depending on a number of distinguishing characteristics. The burden obviously increases cumulatively with the number of risk factors borne by an individual. This study considered only those risk factors [4] that were the main focus of the Uganda NCDs baseline population-based survey conducted in the year 2014. The five risk factors considered in the assessment were; daily smoking, consumption of less than five servings of fruit and vegetables per day, low physical activity levels, the high body mass index and raised blood pressure. In Uganda, prevalence of these risk factors has previously not been established nationally. However, some local area, small sample studies attempted to estimate the factors associated with NCDs [5-7]. Theoretically, the number of NCDs exhibited is a function of modifiable and non-modifiable factors [8-11] and is clearly assessed under data management section. Measurement of the burden of NCDs is a statistical problem whose solution lies in studies that evaluate the dynamics of NCD risk factors [12, 13]. Prevalence and incidences computed by WHO funded studies and others tend to estimate, although done scientifically, predicting the rates of occurrence and re-occurrence of NCD risk factors is yet another area of study $[14,15]$.

\section{Non-communicable diseases and their risk factors in Uganda}

Uganda is one of the countries found in Sub-Saharan Africa where the burden of NCDs in terms of disabilityadjusted life-years increases and continues to stress the already stressed and under-resourced health systems. The rising burden from NCDs, therefore, poses new challenges on the health system requiring more investments in sensitization, besides treatment.

Findings from the NCD risk factor baseline survey in Uganda reveal a high prevalence of hypertension at
$26.5 \%$ among adults aged 18 to 64 years, with no significant differences between the four regions of Uganda [16]. Physical activity is a major risk of NCDs with 94.3\% of participants in Uganda reported to meet the WHO threshold. Work-related physical activity of moderate intensity, and travel-related physical activity contribute most to the overall weekly duration, each contributing 49.6 and $25.2 \%$ respectively [17]. The overall prevalence of impaired fasting glucose in Uganda is estimated to be $2.0 \%$, whereas that of diabetes mellitus is $1.4 \%$. The prevalence of impaired fasting glucose is more (2.1\%) among males than females $(1.9 \%)$, whereas that of diabetes mellitus is 1.6 and $1.1 \%$, respectively. The prevalence of both impaired fasting glucose and diabetes mellitus is comparatively low in Uganda, but significantly more among urban than rural dwellers; with most of the population not aware of their status [18]. Overall, the risk factors and disease burden posed by the NCDs are more prevalent in the elderly than the youth [19-22].

The main objective of this study was to assess the dynamics of factors associated with risk factors of NCDs in Uganda through establishing predictors for the number of risk factors exhibited by adults aged 18 to 69 years. The study also determined the prevalence for the number of key NCD risk factors exhibited. Subsequently, the probability of acquiring a certain level of risk factors was derived. This study augurs well with the WHO objective number six which focuses on monitoring trends and the social economic determinants of NCDs [23, 24].

\section{Methods}

\section{Data sources}

The study is based on analysis of data from a population based survey, which followed the WHO STEPwise approach to surveillance (STEPS) on risk factors for NCD $[1,25]$. The survey had three parts. The first part of the survey (STEP 1) comprised of the collection of sociodemographic and behavioral information. This included the Global Physical Activity Questionnaire (GPAQ) for physical activity surveillance across countries $[1,26,27]$. The GPAQ was used to collect data on physical activity participation in three settings as well as on sedentary 
behavior, comprising of 16 questions. The domains included activity at work; travel to and from places and recreational activities. The second part of the survey (STEP 2) comprised of the collection of physical measurements such as height, weight, blood pressure, waist and hip circumference. The third part (STEP 3) comprised of the measurement of biochemical parameters to assess blood levels of total cholesterol (TC), High Density Lipoprotein cholesterol (HDL-C) and fasting blood glucose (FBG).

Participants in the survey were informed and their consent sought so as to get involved in the data collection for two consecutive days. First day was for providing responses to the survey questionnaire and taking of physical measurements of weight, height and waist circumference (STEP 1 and STEP 2), while the second day was used to measure fasting biochemical parameters using finger prick blood samples. All participants were requested to fast for at least 8 hours overnight for STEP 3 and not to indulge in exercise or smoking in the morning before data collection.

STEP 1 and 2 were carried out in the participant's home. For STEP 3, participants were met at an agreed place in the enumeration area starting from 7:00 am. A blood sample from a finger prick for the measurement of TC, HDL-C and FBG was then taken and analysis done using the CardioChek ${ }^{\bullet}$ PA meter. Most of the participants had a very short distance to walk, and if substantial distance was envisaged, they came on a motorcycle or would be collected by the survey team vehicle. Participants eligible for blood sample collection were those who had an overnight 8-hour fasting with no exercise in the morning and did not smoke $[28,29]$.

\section{Data management}

Five risk factors found to be associated with NCDs were used to generate the derived dependent variable (DDV). These were; tobacco smoking, less than five servings of fruit and vegetables per day, low physical activity levels, high body mass index and raised blood pressure. These were generated from an aggregation of related indicators for each of the five mentioned, thus, each of them represents a risk factor for the NCDs. For example, the indicator for smoking was derived from the questions; "Do you currently smoke any tobacco products, such as cigarettes, cigars, shisha or pipes?" and "Do you currently smoke tobacco products daily?" After data cleaning, dummy variables were generated for each. For the case, of smoking, it was ' 0 ' when the response to the first question was 'No' and the response to the second question was 'No' otherwise coded as ' 1 ' for "Yes". Subsequently, row totals were generated for the five indicator variables to show the number of NCD risk factors per respondent.
The study employed a mixture of variables of different measurement scales for the independent variables. They include endogenous predictors, such as; systolic blood pressure, diastolic blood pressure and body mass index and the exogenous predictors such as; the number of daily fruit and vegetable servings consumed per day, location, residence, type of dwelling and land tenure system. Other personal predictors considered in the study included; age and sex of the respondent $[7,16,25,28$, 30] as presented in Table 1. All variables underwent thorough data cleaning and verification before generating the risks and composite indicator. To avoid strong autocorrelations, correlation coefficients between the DDV and the predictors were generated and only those with correlation coefficients less than $| \pm 0 \cdot 37|$ were considered for modeling. The study used the following definition for a risk factor as that portion or category of a variable whose continued co-existence or magnitude may endanger life of the host or subject. For example, low physical activity level is a risk factor, but physical activity itself is not; similarly, whereas high body mass index is a risk factor, body mass index itself is not. Thus the DDV was composited to a discrete numerical random variable that holds the counts per individual of the number of NCD risk factors.

\section{Statistical modeling}

The multinomial logistic regression model, a statistical standard approach was employed to assess the dynamics of NCDs risk factors in Uganda, [31, 32]. This was applied conditional to the measurement level of modeling for the derived dependent variable (DDV) [33]. Under this modeling approach, the response variable was generated with three categories: $0=$ "No risk factor", $1=$ " 1 and 2 risk factors" and $2=$ " 3 and more risk factors". We modeled DDV as a polytomous response variable, to estimate the probability of occurrence of the different categories [32]. Cognizant of the fact that we were assessing determinants for occurrence of the categories of NCDs, rather than the levels of occurrence of the NCDs. Therefore, the multinomial logit model (MLM) was a natural choice, taking the form;

$$
\frac{p\left(Y_{i}=k\right)=e^{\beta_{k}^{\prime} X_{i}}}{1+\sum_{k=1}^{K-1} e^{\beta_{k}^{\prime} X_{i}}}
$$

The index, $i$ is a set of predictors $\{1,2 \ldots\}$ while $\mathrm{k}$ represents a set of categories for the response category, $\mathrm{Y}$ with the range belonging to the set $\{0,1,2\}$ for the 3 categories of NCDs as classified. We chose $\mathrm{k}=0$ as a suitable base category against which the other categories are compared. The exponential beta coefficients thus represent the change in the odds of the response variable 
Table 1 Description and measurement levels for the model variables

\begin{tabular}{|c|c|c|c|}
\hline Number & Study variable & Variable definition & Measurement level \\
\hline \multirow[t]{5}{*}{1} & \multirow{5}{*}{$\begin{array}{l}\text { Risk factors for the derived } \\
\text { dependent variable (DDV) }\end{array}$} & Daily tobacco smoking & Nominal \\
\hline & & $\begin{array}{l}\text { Less than five servings of fruit } \\
\text { and vegetables per day }\end{array}$ & Nominal \\
\hline & & Low physical activity levels & Nominal \\
\hline & & High body mass index & Nominal \\
\hline & & Raised blood pressure & Nominal \\
\hline \multirow[t]{6}{*}{2} & \multirow{6}{*}{$\begin{array}{l}\text { Endogenous observable factors } \\
\text { (all had weak correlation coefficients } \\
\text { with DDV of } r< \pm 0 \cdot 37 \text { ) }\end{array}$} & Age & Interval \\
\hline & & $\mathrm{BMI}$ & Ratio \\
\hline & & SBP & Interval \\
\hline & & $\mathrm{DBP}$ & Interval \\
\hline & & Servings & Interval \\
\hline & & Sex & Nominal \\
\hline \multirow[t]{4}{*}{3} & \multirow[t]{4}{*}{ Exogenous observable factors } & Region & Nominal \\
\hline & & Residence & Nominal \\
\hline & & Type of residence & Nominal \\
\hline & & Land tenure system & Nominal \\
\hline
\end{tabular}

being in a particular category versus the reference category, associated with a one-unit change of the corresponding predictor variable. The usual shortcomings that arise with MLM relying upon the independence of irrelevant alternatives did not affect our model since we minimized chances of existence of irrelevant alternatives by exhausting the choices for the predictor variables.

\section{Results}

\section{Distribution of number of key risk factors per person}

The median number of risk factors per person was established as two risks with the number of NCD tending towards a positively skewed distribution. The proportion of the population exhibiting one or two risk factors was 38 . $6 \%$ each, while about $56 \cdot 1 \%$ had at least two risk factors.

The distribution of exogenous predictors was studied. Table 2 shows details of their relationship with the number of NCD risk factors per person. The relationships of all the four categorical variables, region, residence, type of residence and land tenure system with the number of risk factors were statistically significant $(p<0.05)$. Overall, findings show that residents in the central region were more likely to have at least two NCD risk factors than any other region; followed by western, eastern and northern respectively. Central region hosts Kampala, the capital city of Uganda where most economic activities are carried out, hence making people more vulnerable to NCDs risk factors. Sensitization on the dangers of sedentary life style isn't growing at the same rate. Similarly, urban residents were found to exhibit two or more risk factors than those in rural areas. Urban residence, like living in the central region is characteristic of urbanization that is impacting on the health of the population. Furthermore, differences in environmental factors and living conditions faced by the populations between rural and urban areas may explain differences in the burden of NCDs. Subsistence living conditions in rural areas have a toll on the inhabitants to work harder for their family's survival. It was not surprising that respondents living in tenement type of residence registered more NCD risk factors than those living in independent residents. And similarly, respondents living in rented land tenure system had a higher significant association with two or more risk factors than those who own the land they lived on.

The distributions of observable endogenous numerical predictors were studied. Table 3 shows the descriptive statistics and their relationship with number of NCD risk factors exhibited. An assessment of the relationship among the five numerical variables; age, body mass index, systolic blood pressure, diastolic blood pressure and fruit and vegetable servings per day is presented. As before, there is a consistent increase in the number of NCD risk factors with the increases in age, body mass index, systolic blood pressure, and diastolic blood pressure. The number of fruit and vegetable servings per day was found to have an inverse association with NCD risk factors exhibited by an individual; implying consumption of more fruits and vegetables reduces NCD risk factors.

\section{Multivariate model for effects of key risk factors}

To study, the dynamics of the multivariate effect of each of the factors on NCD risk factors, robust relative risk ratios were generated, by fitting a multinomial logit model (MLM) with results presented in Table 4. 
Table 2 Relationship between non-communicable disease risk factors and exogenous characteristics

\begin{tabular}{|c|c|c|c|c|c|c|c|}
\hline Number of risk factors & $\begin{array}{l}\text { 0-risk factors } \\
(\%)\end{array}$ & $\begin{array}{l}\text { 1-risk factor } \\
\text { (\%) }\end{array}$ & $\begin{array}{l}\text { 2-risk factors } \\
(\%)\end{array}$ & $\begin{array}{l}\text { 3-risk factors } \\
(\%)\end{array}$ & $\begin{array}{l}\text { 4-risk factors } \\
(\%)\end{array}$ & $\begin{array}{l}\text { 5-risk factors } \\
(\%)\end{array}$ & $\begin{array}{l}\text { Sample distribution } \\
\text { (n) }\end{array}$ \\
\hline \multicolumn{8}{|l|}{ Region } \\
\hline Northern & $5 \cdot 8$ & $43 \cdot 4$ & $38 \cdot 3$ & $10 \cdot 6$ & $1 \cdot 8$ & $0 \cdot 0$ & 707 \\
\hline Eastern & $6 \cdot 9$ & $40 \cdot 3$ & $37 \cdot 3$ & $12 \cdot 5$ & $3 \cdot 2$ & $0 \cdot 0$ & 1,036 \\
\hline Central & $3 \cdot 9$ & $35 \cdot 8$ & $39 \cdot 4$ & $17 \cdot 3$ & $3 \cdot 5$ & $0 \cdot 1$ & 1,359 \\
\hline Western & $5 \cdot 2$ & $37 \cdot 2$ & $39 \cdot 1$ & $15 \cdot 6$ & $2 \cdot 9$ & $0 \cdot 0$ & 885 \\
\hline \multicolumn{8}{|l|}{$x^{2}=44 \cdot 16 ; p=0.000$} \\
\hline \multicolumn{8}{|l|}{ Residence } \\
\hline Urban & $3 \cdot 7$ & $33 \cdot 0$ & $39 \cdot 9$ & $18 \cdot 9$ & $4 \cdot 5$ & $0 \cdot 0$ & 1,084 \\
\hline Rural & $5 \cdot 9$ & $40 \cdot 7$ & $38 \cdot 1$ & $12 \cdot 8$ & $2 \cdot 5$ & $0 \cdot 0$ & 2,903 \\
\hline \multicolumn{8}{|l|}{$x^{2}=51 \cdot 74 ; p=0.000$} \\
\hline \multicolumn{8}{|l|}{ Type of residence } \\
\hline $\begin{array}{l}\text { Independent } \\
\text { housing }\end{array}$ & $5 \cdot 4$ & $39 \cdot 0$ & $38 \cdot 1$ & $14 \cdot 7$ & $2 \cdot 9$ & $0 \cdot 0$ & 2,682 \\
\hline Tenement & $2 \cdot 1$ & $31 \cdot 7$ & $45 \cdot 0$ & $17 \cdot 3$ & $3 \cdot 9$ & $0 \cdot 0$ & 716 \\
\hline Independent flat & $0 \cdot 0$ & $47 \cdot 8$ & $30 \cdot 4$ & $21 \cdot 7$ & $0 \cdot 0$ & $0 \cdot 0$ & 23 \\
\hline Sharing & $0 \cdot 0$ & $40 \cdot 0$ & $36 \cdot 7$ & $21 \cdot 7$ & $1 \cdot 7$ & $0 \cdot 0$ & 60 \\
\hline Boys Quarters & $0 \cdot 0$ & $42 \cdot 1$ & $42 \cdot 1$ & $10 \cdot 5$ & $5 \cdot 3$ & $0 \cdot 0$ & 19 \\
\hline Garage & $0 \cdot 0$ & $0 \cdot 0$ & $50 \cdot 0$ & $50 \cdot 0$ & $0 \cdot 0$ & $0 \cdot 0$ & 2 \\
\hline Hut & $11 \cdot 1$ & $46 \cdot 6$ & $32 \cdot 9$ & $6 \cdot 6$ & $2 \cdot 6$ & $0 \cdot 2$ & 468 \\
\hline Other & $0 \cdot 0$ & $38 \cdot 5$ & $15 \cdot 4$ & $38 \cdot 5$ & $7 \cdot 7$ & $0 \cdot 0$ & 13 \\
\hline \multicolumn{8}{|l|}{$x^{2}=136 \cdot 22 ; p=0.000$} \\
\hline \multicolumn{8}{|l|}{ Land Tenure System } \\
\hline Owned & $6 \cdot 1$ & $39 \cdot 6$ & $37 \cdot 8$ & $13 \cdot 8$ & $2 \cdot 7$ & $0 \cdot 0$ & 3,011 \\
\hline Rented & $1 \cdot 7$ & $34 \cdot 1$ & $43 \cdot 2$ & $16 \cdot 9$ & $4 \cdot 2$ & $0 \cdot 0$ & 789 \\
\hline Supplied & $1 \cdot 8$ & $40 \cdot 4$ & $31 \cdot 6$ & $21 \cdot 1$ & $5 \cdot 3$ & $0 \cdot 0$ & 57 \\
\hline Supplied & $10 \cdot 0$ & $47 \cdot 3$ & $31 \cdot 8$ & $8 \cdot 2$ & $2 \cdot 7$ & $0 \cdot 0$ & 110 \\
\hline Other & $13 \cdot 3$ & $20 \cdot 0$ & $46 \cdot 7$ & $20 \cdot 0$ & $0 \cdot 0$ & $0 \cdot 0$ & 15 \\
\hline$x^{2}=63 \cdot 99 ; p=0.000$ & & & & & & & \\
\hline
\end{tabular}

From the MLM, two models were derived; one for determinants of 1 or 2 risk factors and the other for determinants of 3 to 5 risk factors. The category 0 ' $=0$ risk factors' was used as the base or reference category. With exception of diastolic blood pressure, all the other endogenous observable factors, including; age, body mass index, systolic blood pressure, diastolic blood pressure and fruit and vegetable servings increased and had significant $(p<0 \cdot 05)$ effects on the risk factors. Fruit and vegetable servings per day significantly reduce the NCD risk factors exhibited by factors of 0.658 and 0.531 for the 1 or 2 and 3 to 5 risk factors models respectively. Findings also showed that the constant that is, the effect on the mean number of NCD risk factors exhibited with no predictors was statistically significant.

The dynamic variations of exogenous observable factors were examined. Generally, the study established that living in the eastern region was a significant predictor of the first category ( 1 or 2 risk factors) of NCD risk factors exhibited, but not for the category 3 to 5 risk factors. Comparing the urban residents, living in a rural area significantly increased the risk of having 1 or 2 risk factors by a multiple of 1.545 . For type of residence, the relative risk ratios were all positive. With independent-house as a reference category, living in a hut, garage, boys' quarters or sharing significantly increased the chances of exhibiting 1 or 2 risk factors by over 1.3. Analysis of land tenure system revealed that for the land 'supplied free or rent paid by relative or other person' was a statistically significant predictor for NCD risk factors exhibited $(p<$ $0.05)$ and could reduce the risk by a factor of 0.683 and 0.759 for the ' 1 or 2 ' and ' 3 to 5 ' risk factors respectively.

\section{Discussions}

This study presents a novel framework that explores predictors of the risk factors associated with NCDs. The 
Table 3 Distribution of NCDs by observable endogenous characteristics

\begin{tabular}{|c|c|c|c|c|c|c|}
\hline \multicolumn{2}{|c|}{ Number of NCD risk factors } & \multirow{2}{*}{$\frac{\text { Age }}{211}$} & \multirow{2}{*}{$\begin{array}{l}\text { Body mass index } \\
211\end{array}$} & \multirow{2}{*}{$\begin{array}{l}\text { Systolic blood pressure } \\
211\end{array}$} & \multirow{2}{*}{$\begin{array}{l}\text { Diastolic blood pressure } \\
211\end{array}$} & \multirow{2}{*}{$\begin{array}{l}\text { Fruit and vegetable servings } \\
208\end{array}$} \\
\hline 0 risk factors & $\mathrm{n}$ & & & & & \\
\hline & $\bar{x}$ & 33.71 & 20.95 & 118.42 & 77.95 & 8.58 \\
\hline & s & 12.81 & 2.11 & 9.72 & 6.67 & 4.26 \\
\hline \multirow[t]{3}{*}{1 risk factor } & $n$ & 1539 & 1499 & 154 & 1539 & 1531 \\
\hline & $\bar{x}$ & 33.25 & 21.39 & 117.69 & 76.73 & 2.65 \\
\hline & $s$ & 12.30 & 2.48 & 15.63 & 10.28 & 3.15 \\
\hline \multirow[t]{3}{*}{2 risk factors } & $n$ & 1539 & 1363 & 1539 & 1539 & 1538 \\
\hline & $\bar{x}$ & 35.54 & 23.41 & 121.70 & 79.35 & 2.14 \\
\hline & s & 12.85 & 6.51 & 29.23 & 18.40 & 2.27 \\
\hline \multirow[t]{3}{*}{3 risk factors } & $n$ & 577 & 502 & 577 & 577 & 577 \\
\hline & $\bar{x}$ & 39.61 & 26.96 & 131.37 & 85.72 & 1.87 \\
\hline & s & 13.69 & 14.60 & 34.66 & 22.52 & 1.64 \\
\hline \multirow[t]{3}{*}{4 risk factors } & $n$ & 120 & 114 & 120 & 120 & 120 \\
\hline & $\bar{x}$ & 43.30 & 30.03 & 150.06 & 97.36 & 1.54 \\
\hline & s & 13.51 & 24.29 & 27.80 & 18.93 & 1.15 \\
\hline \multirow[t]{3}{*}{5 risk factors } & $\mathrm{n}$ & 1 & 0 & 1 & 1 & 1 \\
\hline & $\bar{x}$ & 69.00 & - & 138.00 & 101.50 & 0.43 \\
\hline & s & - & - & - & - & - \\
\hline
\end{tabular}

Note: $n$ sample size distribution, $\bar{x}$ average, $s$ standard deviation, - implies no statistic to report

burden faced by individuals due to cumulative risk factors for NCDs was assessed including their prevalence rates and is demonstrated in Fig. 1.

This study defined a 5-category NCD risk factor to include; daily tobacco use, less than 5-daily servings of fruits and vegetables, low physical activity than WHO recommendation, high BMI and raised blood pressure. These variables were used to categorize and generate an index for number of risk factors. Further, three categories of risk factors were generated where a participant could present with none of them, one or two, and three or more risk factors. The significant proportion of the participants, $77 \%$ exhibited one or two of the risk factors (38.5\% each) and over $90 \%$ exhibited at least 1 risk factor. These high proportions could have a significant influence on the productivity of the individual, increased burden on the healthcare system and eventually stifle economic development.

Evidently, as our findings show, NCD risk factors are on the increase and so are the variations in their associated factors relational and causal fcators [34, 35]. Relatedly, there are also variations in cumulative risk factors due to non-communicable diseases that directly affect the disease burden in families and communities. For instance, for two participants, while holding other factors constant, the one with two or more risks supposedly experiences greater disease burden than the one with one disease risk factor.
The effects of the risk factors derived from our model concur with predictors of the NCDs as noted in other studies [36-39]. For instance, there is a significant direct relationship between the number of NCD risk factors with body mass index, systolic blood pressure, but an inverse relationship with consumption of fruit and vegetables. Thus, higher BMI, systolic blood pressure and consumption of less than five servings of fruits and vegetables per day increases the relative risks of more cumulative NCD risk factors. A number of exogenous observable factors including: region, residence, type of residence and land tenure system significantly determine the cumulative number of risk factors for the NCDs. Participants residing in the urban areas were more likely to have two or more risk factors than those in rural areas. Related studies concur that urban residence is a primary risk factor for NCDs impacting on the health of the population $[20,40,41]$. Regionally, in Uganda, urbanization is more realized in the central region, and this, too was significantly associated with number of NCD risk factors. Differences in exogenous observable factors and living conditions of the population between rural and urban areas explain differences in the burden of NCDs. Subsistence living conditions in rural areas have a toll on the inhabitants forcing them to work sometimes under very difficult conditions for their family's survival. Participants living in a hut had less likelihood of increased NCD risk factors. 
Table 4 Determinants of cumulative risk factors associated with non-communicable diseases in Uganda

\begin{tabular}{|c|c|c|c|c|}
\hline \multirow{2}{*}{$\begin{array}{l}\text { Reference category: } 0 \text { Risk } \\
\text { Factors }\end{array}$} & \multicolumn{2}{|c|}{1 or 2 Risk Factors } & \multicolumn{2}{|c|}{3 to 5 Risk Factors } \\
\hline & RRR & $p$-value & RRR & $p$-value \\
\hline Age & $1 \cdot 024$ & 0.000 & $1 \cdot 056$ & 0.000 \\
\hline Body Mass Index & $1 \cdot 217$ & 0.000 & $1 \cdot 407$ & 0.000 \\
\hline Systolic Blood Pressure & $1 \cdot 039$ & 0.000 & $1 \cdot 056$ & 0.000 \\
\hline Diastolic Blood Pressure & $1 \cdot 008$ & $0 \cdot 348$ & $1 \cdot 070$ & 0.000 \\
\hline Fruit vegetable servings & $0 \cdot 658$ & 0.000 & 0.531 & 0.000 \\
\hline \multicolumn{5}{|l|}{ Region } \\
\hline Northern ${ }^{a}$ & $1 \cdot 000$ & - & $1 \cdot 000$ & - \\
\hline Eastern & $1 \cdot 349$ & 0.000 & $1 \cdot 403$ & $0 \cdot 116$ \\
\hline Central & $1 \cdot 501$ & $0 \cdot 240$ & $1 \cdot 858$ & 0.017 \\
\hline Western & $0 \cdot 780$ & 0.044 & 0.922 & $0 \cdot 728$ \\
\hline \multicolumn{5}{|l|}{ Residence } \\
\hline Urban $^{a}$ & $1 \cdot 000$ & - & $1 \cdot 000$ & - \\
\hline Rural & $1 \cdot 545$ & 0.000 & $1 \cdot 157$ & $0 \cdot 376$ \\
\hline \multicolumn{5}{|l|}{ Sex } \\
\hline Male $^{a}$ & $1 \cdot 000$ & & $1 \cdot 000$ & \\
\hline Female & $0 \cdot 851$ & 0.697 & 0.836 & 0.636 \\
\hline \multicolumn{5}{|l|}{ Type of residence } \\
\hline Independent house $\mathrm{a}^{\mathrm{a}}$ & $1 \cdot 000$ & - & $1 \cdot 000$ & - \\
\hline Tenement & $0 \cdot 855$ & $0 \cdot 698$ & $0 \cdot 863$ & $0 \cdot 089$ \\
\hline Independent & $1 \cdot 800$ & 0.000 & 1.700 & 0.000 \\
\hline Sharing house/flat/apartment & $1 \cdot 670$ & 0.000 & 1.670 & $0 \cdot 000$ \\
\hline Boys Quarters & $1 \cdot 800$ & 0.000 & 1.450 & 0.000 \\
\hline Garage & $1 \cdot 600$ & 0.000 & 1.380 & 0.000 \\
\hline Hut & $1 \cdot 273$ & 0.000 & $0 \cdot 888$ & $0 \cdot 229$ \\
\hline Other & 1.268 & 0.000 & 1.560 & 0.000 \\
\hline \multicolumn{5}{|l|}{ Land Tenure System } \\
\hline Owned ${ }^{a}$ & $1 \cdot 000$ & - & $1 \cdot 000$ & - \\
\hline Rented & $3 \cdot 739$ & 0.091 & $4 \cdot 196$ & $0 \cdot 066$ \\
\hline Supplied free by employer & $1 \cdot 052$ & $0 \cdot 945$ & $1 \cdot 537$ & $0 \cdot 666$ \\
\hline $\begin{array}{l}\text { Supplied free or rent paid by } \\
\text { relative or other person }\end{array}$ & $0 \cdot 683$ & 0.046 & $0 \cdot 759$ & 0.009 \\
\hline Other & $0 \cdot 924$ & $0 \cdot 790$ & $2 \cdot 844$ & 0.000 \\
\hline Constant & $0 \cdot 002$ & 0.000 & $0 \cdot 000$ & 0.000 \\
\hline
\end{tabular}

Note: $R R R$ relative risk ratio, $D V$ dependent variable, $N C D$ non-communicable disease

Bold $p$-values indicate significant categories; ${ }^{a}$ a reference category with RRR $=1.000$ and un-computed $p$-values; - implies no statistic to report

A hut in the context of Uganda is a proxy indicator for poverty, which measures the level of difficulty of earning a living. Given that over $90 \%$ of the participants met the WHO physical activity requirement, this factor was dropped during the analysis phase [17]. Findings about land tenure system reveal that persons living on land supplied free by the employer bore reduced chances of having multiple NCD risk factors. Land in Uganda is mainly under private ownership, making it very expensive for individuals to acquire. However, given that it is not sustainable for every employer or otherwise to give free land to employees, government needs to regulate the cost of land so as it is more affordable.

\section{Conclusions}

In this study, we assessed determinants for cumulative risk factors of an individual participant associated with NCDs and subsequent burden this causes. Findings show that besides the endogenous factors such as; body 


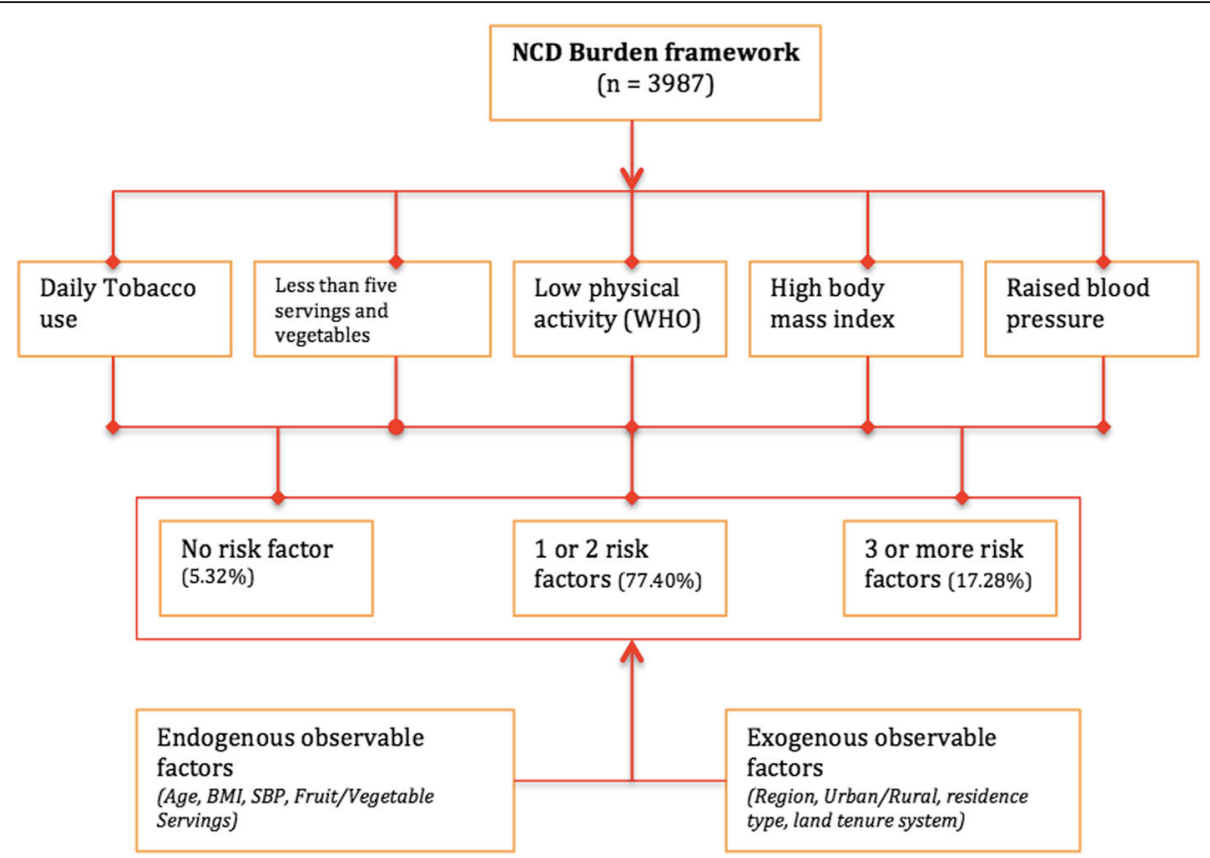

Fig. 1 Framework for the burden of cumulative risk factors for non-communicable diseases

mass index, blood pressure and consumption of fruit and vegetables, there were significant effects on the NCD risk factors among participants predisposed to exogenous factors such as region, residence status and land tenure system. The study showed that risk factors associated with NCDs are on the increase resulting in the burden due of cumulative risk factors presented by an individual. This burden due to risk factors of the NCDs manifests itself in many ways including; late presentation due to the inability of the majority to go for regular tests mainly because they cannot afford the costs of testing and treatment itself. As a consequence of late presentation arises the multiple patient-complications such as blindness, kidney diseases, stroke and heart attacks. With the compounding high poverty rates, the ultimate burden results in high rates of morbidity and mortality.

Notwithstanding, the study was affected by sampling error and some biases in the data due to refusals, especially when it came to testing for diabetes and the requirements such as fasting before blood glucose, measurements could be obtained accurately. Consequently, risk factors of NCDs were restricted to a limited set of predictors.

Despite those limitations, findings of this study provide an indication, both in magnitude and direction of the burden of cumulative risk factors to the general population and specifically to persons living with NCD (s) and the distribution of NCD burden nationally. Therefore in developing interventions to combat NCD prevalence, the government of Uganda needs to employ a more holistic approach to develop and operationalize NCD policy. The policy should provide measurable indicators for each NCD and associated risk factors; a strategy for prevention of harmful use of alcohol and a ban on consumption of unrecorded alcohol and regular national NCD health education. Guidelines, such as NCD screening, diet and physical activity and IEC materials on NCD prevention and control should be developed and translated in local languages. Specifically, the Government of Uganda should reduce the equity gap between rural and urban residents through actions geared to service delivery towards on social, economic and environmental welfare. The Ministry of Health $(\mathrm{MOH})$ should elevate the NCD Desk into a Directorate with a reasonable budget. This could help to implement NCD preventive measures so as to promote equity to access health services including sensitization drives that increase awareness and change attitudes to lifestyle factors.

This study was the first to assess the burden imposed by the cumulative risk factors associated with NCDs. We recommend a study on causal relationships between potential risk factors and NCDs. The Ministry of Health in Uganda, in collaboration with statistical research organizations should institute a more comprehensive national survey to determine the interplay of socio-economic, environmental and cultural factors on the cumulative number of risk factors associated with the Non-Communicable Diseases.

\section{Abbreviations}

BMI: Body mass index; DDV: Derived dependent variable; FBG: Fasting blood glucose; HDL-C: High-density lipoprotein cholesterol; IEC: Information Education and Communication; MLM: Multinomial logistic model; $\mathrm{MOH}$ : Ministry of health; NCDs: Non-communicable diseases; TC: Total cholesterol; UNCST: Uganda national council for science and technology; WHO: World Health Organization 


\section{Acknowledgement}

The authors are grateful to the research participants who volunteered to participate in the NCD risk factor prevalence survey; and for the technical and administrative support provided by Uganda's Ministry of Health, and that from the Uganda Bureau of Statistics. The authors also acknowledge the technical support provided by Melanie Cowan and Lubna Ishaq Bhatti of the Surveillance and Population-based Prevention Unit, Department of Prevention of Noncommunicable Diseases, Non-communicable Diseases and Mental Health Cluster, World Health Organization, Geneva, Switzerland.

\section{Funding}

This baseline survey was co-funded by Ministry of Health, Uganda, World Health Organization, World Diabetes Foundation and United Nations Development Program. The funders had no role in the study design, data collection, analysis and modeling, decision to publish, or preparation of this manuscript.

\section{Availability of data and materials}

The data used in this study can be accessed as at the following uniform resource locator: https://ndownloader.figshare.com/files/4497502.

\section{Authors' contributions}

RW, DG, SKB, GM, FN and JM conceived and designed the study. RW, SKB, GM, JM and GD conducted the study. RW, FN, DG performed data management, analysis and modeling. RW, FN wrote the manuscript. All the authors read and approved the final manuscript.

\section{Competing interests}

The authors declare that there are no competing interests.

\section{Ethics approval and consent to participate}

The conduct of the survey was approved by the Institutional Review Committee of Nsambya Hospital, Kampala, Uganda, and registered by the Uganda National Council for Science and Technology (UNCST). Written informed consent was obtained from eligible subjects before enrollment in the study. Participants with at least two systolic blood pressure readings of at least $120 \mathrm{mmHg}$, and/or diastolic blood pressure of at least $80 \mathrm{mmHg}$, and/or with fasting plasma glucose of at least $6.1 \mathrm{mmol} / \mathrm{L}$, and were not already on treatment for hypertension and/or diabetes, were advised to report to the nearest government owned health facility for further evaluation as soon as possible.

\section{Author details}

'School of Statistics and Planning, Makerere University, Kampala, Uganda. ${ }^{2}$ School of Public Health, Makerere University, Kampala, Uganda. ${ }^{3}$ Department of Internal Medicine St. Francis Hospital Nsambya, Kampala, Uganda. ${ }^{4}$ Control of Non-communicable Diseases Desk, Ministry of Health, Kampala, Uganda. ${ }^{5}$ Office of DVC, Kyambogo University, Kampala, Uganda. ${ }^{6}$ Division of Socioeconomic Surveys, Uganda Bureau of Statistics, Kampala, Uganda. ${ }^{7}$ East African Statistics Institute, Kampala, East Africa, Uganda.

\section{Received: 6 July 2016 Accepted: 25 November 2016}

\section{Published online: 01 December 2016}

\section{References}

1. World Health Organization. STEPS instruments for NCD risk factors (core and expanded version 1.4): the WHO STEPwise approach to Surveillance of noncommunicable diseases (STEPS). 2001

2. Pearce N, Ebrahim S, McKee M, Lamptey P, Barreto ML, Matheson D, Walls H, Foliaki S, Miranda J, Chimeddamba O. The road to 25x 25: how can the five-target strategy reach its goal? Lancet Glob Health. 2014;2:e126-8.

3. Wesonga R, Owino A, Ssekiboobo A, Atuhaire L, Jehopio P. Health and human rights: a statistical measurement framework using household survey data in Uganda. BMC Int Health Hum Rights. 2015;15.

4. Cureau FV, Duarte P, Santos DL, Reichert FF. Clustering of risk factors for non-communicable diseases in Brazilian adolescents: Prevalence and correlates. J Phys Act Health. 2014;11.

5. Mondo CK, Otim MA, Akol G, MuSoke R, Orem J. The prevalence and distribution of non-communicable diseases and their risk factors in Kasese district, Uganda: cardiovascular topics. Cardiovasc J Afr. 2013;24:52-7.
6. Wamala JF, Karyabakabo Z, Ndungutse D, Guwatudde D. Prevalence factors associated with hypertension in Rukungiri district, Uganda-a communitybased study. Afr Health Sci. 2009;9:153-60.

7. Semeere AS, Sempa J, Lwanga I, Parkes-Ratanshi R, Kambugu A Hypertension and associated risk factors in individuals infected with HIV on antiretroviral therapy at an urban HIV clinic in Uganda. Lancet Glob Health. 2014;2:S23.

8. Maher D, Waswa L, Baisley K, Karabarinde A, Unwin N, Grosskurth H. Distribution of hyperglycaemia and related cardiovascular disease risk factors in low-income countries: a cross-sectional population-based survey in rural Uganda. Int J Epidemiol. 2011;40:160-71.

9. Jamison DT. Disease and mortality in sub-Saharan Africa. Washington DC: World Bank Publications; 2006

10. Alwan A, MacLean DR, Riley LM, d'Espaignet ET, Mathers CD, Stevens GA, Bettcher D. Monitoring and surveillance of chronic non-communicable diseases: progress and capacity in high-burden countries. Lancet. 2010;376: $1861-8$

11. Martin-Diener E, Meyer J, Braun J, Tarnutzer S, Faeh D, Rohrmann S, Martin BW. The combined effect on survival of four main behavioural risk factors for non-communicable diseases. Prev Med. 2014;65:148-52.

12. Hosseinpoor AR, Bergen N, Kunst A, Harper S, Guthold R, Rekve D, d'Espaignet ET, Naidoo N, Chatterji S. Socioeconomic inequalities in risk factors for non communicable diseases in low-income and middleincome countries: results from the World Health Survey. BMC Public Health. 2012;12:912

13. Rahim HFA, Sibai A, Khader Y, Hwalla N, Fadhil I, Alsiyabi H, Mataria A, Mendis S, Mokdad AH, Husseini A. Non-communicable diseases in the Arab world. Lancet. 2014;383:356-67.

14. Hussain MA, Noorani S, Khan A, Asad H, Rehan A, Kazi A, Baig MZ, Noor A, Aqil A, Bham NS. The role of neighborhood environment in promoting risk factors of cardiovascular disease among young adults: data from middle to high income population in an asian megacity. PLoS One. 2015;10:e0124827.

15. Kotwani P, Kwarisiima D, Clark TD, Kabami J, Geng EH, Jain V, Chamie G, Petersen ML, Thirumurthy H, Kamya MR. Epidemiology and awareness of hypertension in a rural Ugandan community: a cross-sectional study. BMC Public Health. 2013:13:1151.

16. Guwatudde D, Mutungi G, Wesonga R, Kajjura R, Kasule H, Muwonge J, Ssenono V, Bahendeka SK. The epidemiology of hypertension in Uganda: findings from the national non-communicable diseases risk factor survey. PLoS One. 2015;10:e0138991.

17. Guwatudde D, Kirunda B, Wesonga R, Mutungi G, Kajjura R, Kasule H, Muwonge J, Bahendeka SK. Physical activity levels among adults in Uganda: findings from a countrywide cross-sectional survey. J Phys Act Health. 2016; 13(9):938-45.

18. Bahendeka S, Wesonga R, Mutungi G, Muwonge J, Neema S, Guwatudde D. Prevalence and correlates of diabetes mellitus in Uganda: a populationbased national survey. Tropical Med Int Health. 2015:21:405-16.

19. Murray CJ, Vos T, Lozano R, Naghavi M, Flaxman AD, Michaud C, Ezzati M, Shibuya K, Salomon JA, Abdalla S, Aboyans V. Disability-adjusted life years (DALYs) for 291 diseases and injuries in 21 regions, 1990-2010: a systematic analysis for the Global Burden of Disease Study 2010. Lancet. 2013;380: 2197-223.

20. Riha J, Karabarinde A, Ssenyomo G, Allender S, Asiki G, Kamali A, Young EH, Sandhu MS, Seeley J. Urbanicity and lifestyle risk factors for cardiometabolic diseases in rural Uganda: a cross-sectional study. PLoS Med. 2014;11:e1001683.

21. Kabwama SN, Ndyanabangi S, Mutungi G, Wesonga R, Bahendeka SK, Guwatudde D. Tobacco use and associated factors among adults in Uganda: findings from a nationwide survey. Tob Induc Dis. 2016;14:1.

22. Kabwama SN, Ndyanabangi S, Mutungi G, Wesonga R, Bahendeka SK, Guwatudde D. Alcohol use among adults in Uganda: findings from the countrywide non-communicable diseases risk factor cross-sectional survey. Glob Health Action. 2016:9:31302.

23. Atun R, Jaffar S, Nishtar S, Knaul FM, Barreto ML, Nyirenda M, Banatvala N, Piot P. Improving responsiveness of health systems to non-communicable diseases. Lancet. 2013;381:690-7.

24. Munodawafa D, Sookram C, Nganda B. A strategy for addressing the key determinants of health in the African Region. In: Health monitor, vol. 2. 2013.

25. Aryal KK, Mehata S, Neupane S, Vaidya A, Dhimal M, Dhakal P, Rana S, Bhusal CL, Lohani GR, Paulin FH. The burden and determinants of Non communicable diseases risk factors in Nepal: findings from a nationwide STEPS survey. PLoS One. 2015;10, e0134834 
26. Alwan A. Global status report on noncommunicable diseases 2010. Geneva: World Health Organization; 2011.

27. Mendis S, Puska P, Norrving B. Global atlas on cardiovascular disease prevention and control. Geneva: World Health Organization; 2011.

28. Boutayeb A, Boutayeb $\mathrm{S}$. The burden of non communicable diseases in developing countries. International Journal for Equity in Health. 2005;4:2.

29. Houehanou YC, Lacroix P, Mizehoun GC, Preux P-M, Marin B, Houinato DS. Magnitude of cardiovascular risk factors in rural and urban areas in Benin: findings from a nationwide steps survey. PLoS One. 2015;10(5):e0126441.

30. Kontis V, Mathers CD, Rehm J, Stevens GA, Shield KD, Bonita R, Riley LM, Poznyak V, Beaglehole R, Ezzati M. Contribution of six risk factors to achieving the $25 \times 25$ non-communicable disease mortality reduction target: a modelling study. Lancet. 2014;384:427-37.

31. Hosmer Jr DW, Lemeshow S, Sturdivant RX. Applied logistic regression. Hoboken: Wiley; 2013.

32. Agresti A, Kateri M. Categorical data analysis. Berlin: Springer; 2011.

33. Harrell FE. Regression modeling strategies: with applications to linear models, logistic regression, and survival analysis. Berlin: Springer Science \& Business Media; 2013.

34. Asiki G, Murphy G, Nakiyingi-Miiro J, Seeley J, Nsubuga RN, Karabarinde A, Waswa L, Biraro S, Kasamba I, Pomilla C. The general population cohort in rural south-western Uganda: a platform for communicable and noncommunicable disease studies. Int J Epidemiol. 2013;42(1):129-41.

35. Maher D, Sekajugo J. Research on health transition in Africa: time for action. Health Res Policy Syst. 2011;9:10.1186.

36. Kontis V, Mathers CD, Bonita R, Stevens GA, Rehm J, Shield KD, Riley LM, Poznyak V, Jabbour S, Garg RM, Hennis A. Regional contributions of six preventable risk factors to achieving the $25 \times 25$ non-communicable disease mortality reduction target: a modelling study. Lancet Glob Health. 2015;3: e746-57.

37. Dalal S, Beunza JJ, Volmink J, Adebamowo C, Bajunirwe F, Njelekela M, Mozaffarian D, Fawzi W, Willett W, Adami H-O. Non-communicable diseases in sub-Saharan Africa: what we know now. Int J Epidemiol. 2011;40:885-901.

38. Murphy GAV, Asiki G, Ekoru K, Nsubuga RN, Nakiyingi-Miiro J, Young EH, Seeley J, Sandhu MS, Kamali A. Sociodemographic distribution of noncommunicable disease risk factors in rural Uganda: a cross-sectional study. Int J Epidemiol. 2013:42:1740-53.

39. Mpofu JJ, de Moura L, Farr SL, Malta DC, Iser BM, Bernal RT, Robbins CL, Lobelo F. Associations between noncommunicable disease risk factors, race, education, and health insurance status among women of reproductive age in Brazil-2011. Prev Med Rep. 2016;3:333-7.

40. Teo K, Chow CK, Vaz M, Rangarajan S, Yusuf S. The Prospective Urban Rural Epidemiology (PURE) study: examining the impact of societal influences on chronic noncommunicable diseases in low-, middle-, and high-income countries. Am Heart J. 2009;158:1-7.

41. Kirunda BE, Fadnes LT, Wamani H, Van den Broeck J, Tylleskär T. Populationbased survey of overweight and obesity and the associated factors in periurban and rural Eastern Uganda. BMC Public Health. 2015;15:1.

\section{Submit your next manuscript to BioMed Central and we will help you at every step:}

- We accept pre-submission inquiries

- Our selector tool helps you to find the most relevant journal

- We provide round the clock customer support

- Convenient online submission

- Thorough peer review

- Inclusion in PubMed and all major indexing services

- Maximum visibility for your research

Submit your manuscript at www.biomedcentral.com/submit

) Biomed Central 